\title{
Hubungan Kompensasi, Motivasi dan Kepuasan Kerja dengan Kinerja Dokter Pada BLUD Rumah Sakit Umum Daerah Dr. Loekmono Hadi Kudus
}

\author{
Sudarmono*, Ani Margawati**, Sutopo Patria Jati** \\ *Alumni Magister Ilmu Kesehatan Masyarakat Universitas Diponegoro, **Staf Pengajar Program Magister \\ Ilmu Kesehatan Masyarakat Universitas Diponegoro \\ Email: gusdar1968@gmail.com
}

\section{ABSTRACT}

Since the implementation of the National Health Insurance (JKN) some phycsicians at the hospital have decreased income, the effects are dissatisfaction and the decrease of motivation resulting in the decrease of the physician performance which is manifested in the limitation of the number of patient visits, the transfer of the patient from hospital to private practice or to other hospital and other performance decline manifestations. The purpose of this study is to analyze the relationship between compensation, motivation and job satisfaction with the performance of physicians at BLUD RS $d r$. Loekmono Hadi Kudus.

This research using quantitative method with cross sectional approach. Sources of data in the study is divided into two primary data sources and secondary data. The number of samples in this study were 49 people.

The analysis of this research using univariate analysis showed the result of high category compensation variable equal to $53.1 \%$, job satisfaction variable equal to $51,0 \%$ and work motivation variable equal to $53,1 \%$. While the result of bivariate analysis showed that the variable of compensation, job satisfaction, and motivation have $p$ value less than 0.05 which shows the three variables are related to physician performance and have $p$ value less than 0.25 , so it can be continued to multivariate analysis. While the result of multivariate test by using logistic regression test obtained in work motivation variable got result $p$ value $=0.000$ with $\operatorname{Exp}(B)=8,155$.

The conclusion of this research is physician motivation have influence 8,155 times better than other independent variable. This research recommends that the hospital management to pay attention to career development and promotion system, improve interpersonal communication, give reward to physician and give responsibility according to physician's duty and authority to be able to increase physician's job satisfaction..

Keywords: Compensation; Motivation; Job Satisfaction; Physician

\section{PENDAHULUAN}

Sumber daya manusia merupakan salah satu unsur dalam organisasi yang mempunyai peranan penting, dimana maju mundurnya suatu organisasi bergantung pada peran yang dijalankan oleh orang - orang yang ada di dalamnya. Manusia selain merupakan unsur pelaksana kebijakan-kebijakan dalam organisasi, mereka juga merupakan makhluk yang mempunyai pikiran, perasaan, kebutuhan serta harapan-harapan tertentu. Hal ini sangat memerlukan perhatian tersendiri, karena faktor- 
faktor tersebut akan mempengaruhi prestasi kerja, dedikasi dan loyalitas serta kecintaan terhadap pekerjaan dan perusahaannya. ${ }^{1}$

Rumah Sakit untuk dapat meningkatkan kinerja karyawannya, khususnya dokter, dituntut untuk dapat lebih memperhatikan faktor-faktor yang mempengaruhinya seperti kompensasi yang diberikan pada setiap dokter, kepuasan kerja dan motivasi. Kompensasi, kepuasan dan motivasi kerja dapat mempengaruhi perilaku karyawan untuk bekerja lebih bersemangat dan memacu tingginya kinerja. $^{2}$

Sesuai dengan Peraturan Presiden No. 111 Tahun 2013 tentang Jaminan Kesehatan, pola pembayaran pelayanan kesehatan di tingkat lanjutan oleh BPJS Kesehatan menggunakan sistem pola pembayaran Indonesia Case Based Groups (INA-CBG's). Sejak diterapkannya tarif INA-CBG's, Instalasi Farmasi, Laboratorium dan Radiologi Rumah sakit yang sebelumnya merupakan Revenue Center (pusat pemasukan) dan Profit Center (pusat laba) berubah menjadi Cost Center (pusat biaya). Akibatnya profit Rumah Sakit menurun,idealnya di era JKN dengan meningkatanya jumlah pasien maka pendapatan tenaga medis, termasuk dokter, turut mengalami peningkatan sesuai dengan meningkatnya tindakan yang dilakukan. Ini berarti semakin banyak jumlah pasien yang diterima, maka seharusnya semakin tinggi pula pendapatan tenaga medis. Hal tersebut berdampak pada ketidakpuasan dan turunnya motivasi dokter yang berakibat menurunnya kinerja dokter yang dimanifestasikan pada pembatasan jumlah kunjungan pasien, pengalihan pasien dari RS ke praktik pribadi atau ke Rumah Sakit lainnya dan manifestasi penurunan kinerja pada penurunnan kinerja. ${ }^{3}$

\section{METODOLOGI PENELITIAN}

Penelitian ini merupakan penelitian kuantitatif dengan desain studi deskriptif analitis yang digunakan untuk menguji hipotesis dan melakukan intepretasi terkait dengan hubungan antar variabel penelitian, penelitian ini juga termasuk penelitian cross sectional dimana pengambilan data dilakukan pada satu waktu. ${ }^{4}$ Instrumen dalam penelitian ini adalah angket yang dianalisis dengan menggunakan uji chi square dan regresi logistik. Populasi dalam penelitian ini adalah semua dokter yang bekerja di RS Dr. Loekmono Hadi Kudus sedangkan sampel dalam penelitian ini adalah 49 orang dokter yang bekerja di RS Dr. Loekmono Hadi Kudus yang diambil dengan menggunakan cara purposive sampling.

\section{HASIL}

\section{Karakteristik responden}

Karakteristik dokter yang menjadi responden penelitian sebagian besar berumur 51-60 tahun $(34,7 \%)$ dengan jenis kelamin laki-laki $(51,0 \%)$, tingkat pendidikan dokter spesialis $(63,3 \%)$ dengan masa kerja kurang dari 10 tahun $(44,9 \%)$ dengan tingkat penghasilan 10 25 juta $(49,0 \%)$.

\section{Analisis Univariat}

a. Kompensasi

Tabel 1Distribusi frekuensi kompensasi dokter RSUD dr. Loekmono Hadi Kudus

\begin{tabular}{cccc}
\hline No & $\begin{array}{c}\text { Kontrol } \\
\text { Kekuasaan }\end{array}$ & Frekuensi & $\begin{array}{c}\text { Presentase } \\
(\%)\end{array}$ \\
\hline 1 & Tinggi & 23 & 46,9 \\
\hline 2 & Rendah & 26 & 53,1 \\
\hline & Jumlah & 49 & 100
\end{tabular}

b. Kepuasan kerja

Tabel 2Distribusi frekuensi kepuasan kerja dokter RSUD dr. Loekmono Hadi Kudus

\begin{tabular}{|c|c|c|c|}
\hline No & $\begin{array}{l}\text { Lingkup } \\
\text { Praktek }\end{array}$ & Frekuensi & $\begin{array}{c}\text { Presentase } \\
(\%)\end{array}$ \\
\hline 1 & Tinggi & 25 & 51 \\
\hline 2 & Rendah & 24 & 49 \\
\hline & Jumlah & 49 & 100 \\
\hline
\end{tabular}

c. Motivasi

Tabel 3Distribusi frekuensi motivasi kerja dokter RSUD dr. Loekmono Hadi Kudus

\begin{tabular}{llcc}
\hline No & $\begin{array}{c}\text { Kepentingan } \\
\text { Bersama }\end{array}$ & Frekuensi & $\begin{array}{c}\text { Presentase } \\
(\%)\end{array}$ \\
\hline 1 & Tinggi & 26 & 53,1 \\
\hline 2 & Rendah & 23 & 46,9 \\
\hline
\end{tabular}




\section{Analisis Bivariat}

a. Deskripsi hubungan kompensasi dan kinerja dokter di RSUD Dr. Loekmono Hadi Kudus

Tabel 5 Hubungan kompensasi dan kinerja dokter

\begin{tabular}{ccccccc}
\hline \multirow{2}{*}{$\begin{array}{c}\text { Kompens } \\
\text { asi }\end{array}$} & \multicolumn{4}{c}{ Kinerja } & \multicolumn{2}{c}{ Total } \\
\cline { 2 - 5 } & \multicolumn{2}{c}{ Rendah } & \multicolumn{2}{c}{ Tinggi } & & \\
\cline { 2 - 6 } Rendah & 1 & 78 & $\mathrm{f}$ & $\%$ & $\mathrm{f}$ & $\%$ \\
& 8 & & & & 6 & \\
\hline Tinggi & 5 & 21.74 & 1 & 69.23 & 2 & 46.94 \\
& & & 8 & & 3 & \\
\hline Total & 2 & 100.0 & 2 & 100.0 & 4 & 100.0 \\
& 3 & 0 & 6 & 0 & 9 & 0 \\
\hline
\end{tabular}

$\mathrm{P}=0,002$

b. Deskripsi hubungan kepuasan kerja dan kinerja dokter di RSUD Dr. Loekmono Hadi Kudus

Tabel 6 Hubungan kepuasan kerja dan kinerja dokter

\begin{tabular}{ccccccc}
\hline \multirow{2}{*}{$\begin{array}{c}\text { Kepuasa } \\
\text { n kerja }\end{array}$} & \multicolumn{4}{c}{ Kinerja } & \multicolumn{2}{c}{ Total } \\
\cline { 2 - 5 } & \multicolumn{2}{c}{ Rendah } & \multicolumn{2}{c}{ Tinggi } & & \\
\cline { 2 - 6 } & $\mathrm{f}$ & $\%$ & $\mathrm{f}$ & $\%$ & $\mathrm{f}$ & $\%$ \\
\hline Rendah & 1 & 69.57 & 8 & 30.77 & 2 & 48.98 \\
& 6 & & & & 4 & \\
\hline Tinggi & 7 & 30.43 & 1 & 69.23 & 2 & 51.02 \\
& & & 8 & & 5 & \\
\hline Total & 2 & 100.0 & 2 & 100.0 & 4 & 100.0 \\
& 3 & 0 & 6 & 0 & 9 & 0 \\
\hline $\mathrm{P}=0.015$ & & & & & &
\end{tabular}

c. Deskripsi hubungan motivasi dan kinerja dokter di RSUD Dr. Loekmono Hadi Kudus

Tabel 7 Hubungan motivasi dan kinerja dokter

\begin{tabular}{ccccccc}
\hline \multirow{2}{*}{$\begin{array}{c}\text { Motivas } \\
\mathrm{i}\end{array}$} & \multicolumn{4}{c}{ Kinerja } & \multirow{2}{*}{ Total } \\
\cline { 2 - 5 } & \multicolumn{2}{c}{ Rendah } & \multicolumn{2}{c}{ Tinggi } & & \\
\cline { 2 - 6 } Rendah & 1 & 78.26 & 5 & 19.23 & 2 & 46.94 \\
& 8 & & & & 3 & \\
\hline Tinggi & 5 & 21.74 & 2 & 80.77 & 2 & 53.06 \\
& & & 1 & & 6 & \\
\hline Total & 2 & 100.0 & 2 & 100.0 & 4 & 100.0 \\
& 3 & 0 & 6 & 0 & 9 & 0 \\
\hline $\mathrm{P}=0.000$ & & & & & &
\end{tabular}

4. Analisis Multivariat

Tabel 8 Uji regresi logistik

$\begin{array}{cccc}\text { Variabel } & \text { Nilai } & \text { Signifikasi } & \text { Exp (B) } \\ \text { penelitian } & \text { Koefisien } & & \\ & \text { Regresi } & & \\ & \text { Logistik } & & \end{array}$

(B)

\begin{tabular}{llll}
\hline Kompensasi & 0.985 & 0.239 & 2.677 \\
\hline Motivasi kerja & 2.099 & 0.008 & 8.155 \\
\hline $\begin{array}{l}\text { Kepuasan } \\
\text { kerja }\end{array}$ & 0.471 & 0.565 & 1.602 \\
\hline
\end{tabular}

\section{PEMBAHASAN}

\section{Kompensasi}

Kompensasi merupakan imbalan/balas jasa yang diberikan oleh perusahaan kepada tenaga kerja, karena tenaga kerja tersebut telah memberikan sumbangan dan pikiran demi kemajuan dan kontinuitas perusahaan dalam rangka mencapai tujuan yang telah ditetapkan, baik dalam jangka pendek maupun dalam jangka panjang. ${ }^{5}$ Semakin tinggi kompensasi yang diberikan kepada doktermaka semakin tinggi pula kinerja dokter tersebut, begitupula sebaliknya semakin rendah kompensasi yang diberikan semkin rendah kinerja dokter tersebut.Program kompensasi ini penting bagi karyawan sebagai individu karena besar kompensasi mencerminkan ukuran nilai karya mereka diantara karyawan, keluarga dan masyarakat. Selain itu program kompensasi merupakan salah satu hal terpenting bagi manajemen agar dapat memotivasi karyawan, meningkatkan prestasi kerja dan meningkatkan kinerja karyawan.

\section{Kepuasan Kerja}

Kepuasan kerja merupakan sebuah kondisi menyenangkan atau kondisi emosional positif yang berasal dari penilaian karyawan terhadap pekerjaannya. ${ }^{6}$ Kepuasan kerja merupakan salah satu faktor penting yang mempengaruhi kepuasan hidup seseorang, karena sebagaian besar waktu hidup manusia dihabiskan ditempat kerjanya. Semakin tinggi kepuasan kerja doktermaka semakin tinggi pula kinerja dokter tersebut, begitupula sebaliknya 
semakin rendah kepuasan kerja dokter semakin rendah kinerja dokter tersebut.

\section{Motivasi}

Motivasi merupakan respon karyawan terhadap sejumlah pernyataan mengenai keseluruhan usaha yang timbul dari dalam dirinya agar tumbuh dorongan untuk bekerja dan tujuan yang dikehendaki karyawan tercapai. Motivasi diri yang ada pada karyawan akan membangkitkan kegairahan dalam bekerja dan dapat memacu untuk tetap bertahan ketika terjadi masalah. ${ }^{7}$ Semakin tinggi motivasi doktermaka semakin tinggi pula kinerja dokter tersebut, begitupula sebaliknya semakin motivasi semakin rendah kinerja dokter tersebut.Pemberian motivasi harus menjadi perhatian khusus pihak manajemen karena dapat menjadi salah satu faktor untuk meningkatkan kinerja rumah sakit, dokter sebagai pintu utama dalam memberikan pelayan kesehatan kepada masyarakat dengan motivasi kerja yang tinggi akan memiliki semangat yang tinggi dalam memberikan pelayanan yang terbaik bagi pasien sehingga pasien merasa puas dengan pelayanan yang diberikan.

\section{KESIMPULAN}

1. Karakteristik dokter yang menjadi responden penelitian sebagian besar berumur 51-60 tahun $(34,7 \%)$ dengan jenis kelamin laki-laki $(51,0 \%)$, tingkat pendidikan dokter spesialis $(63,3 \%)$ dengan masa kerja kurang dari 10 tahun $(44,9 \%)$ dengan tingkat penghasilan 1025 juta $(49,0 \%)$.

2. Sebagian besar responden $(53,1 \%)$ memiliki kompensasi yang tinggi, kepuasan kerja yang tinggi $(51,0 \%)$, motivasi kerja yang tinggi $(53,1 \%)$ serta kinerja yang tinggi $(53,1 \%)$.

3. Variabel kompensasi $(\mathrm{p}=0,002)$, kepuasan kerja $(0,015)$ dan motivasi kerja $(0,000)$ berhubungan secara signifikan dengan kinerja dokter di RSUD dr. Loekmono Hadi Kudus.

4. Diantara 3 variabel penelitian: variabel kompensasi, kepuasan kerja dan motivasi kerja, motivasi kerja mempunyai komponen $\operatorname{Exp}(B)$ 8,155 kali pengaruh terhadap kinerja dokter di RSUD dr. Loekmono Hadi Kudus. Hal tersebut menunjukkan motivasi kerja dokter menjadi faktor yang penting untuk meningkatkan kinerja dokter.

\section{DAFTAR PUSTAKA}

1. Hasibuan, Malayu S.P. Manajemen Dasar, Pengertian dan Masalah. Jakarta: PT Gunung Agung.

2. Hasibuan, Malayu S.P. Manajemen: Dasar, Pengertian, dan Masalah Edisi Revisi. Jakarta: Bumi Aksara; 2005.

3. Peraturan Presiden No. 111 Tahun 2013 tentang Jaminan Kesehatan Nasional.

4. Sutrisno, Hadi. Metodologi Research Jilid 3. Yogyakarta: Andi; 2004.

5. Handoko, Hani. Manajemen Personalia dan Sumber Daya ManusiaEdisi Kedua. Yogyakarta: PT. BPFE; 2003.

6. Setiawan, Ivan Aris dan Ghozali, Imam. Akutansi Keperilakuan. Semarang: Badan Penerbit Universitas Diponegoro; 2006.

7. Rivai, Veithzal. Manajemen Sumber Daya Manusia untuk Perusahaan dari Teori ke Praktik. Jakarta: PT. Raja Grafindo Persada; 2005. 